\title{
DC Elektrikli Raylı Sistemler İçin Teknik ve Ekonomik Açıdan Verimlilik Analizi
}

\author{
Ahmet Y1ldiz ${ }^{*}$, Oktay Arıkan ${ }^{2}$ \\ 1 Yıldız Teknik Üniversitesi, Elektrik-Elektronik Fakültesi, Elektrik Mühendisliği Bölümü, İstanbul, Türkiye (ORCID: 0000-0000-0000-0000) \\ ${ }^{2}$ Yıldız Teknik Üniversitesi, Elektrik-Elektronik Fakültesi, Elektrik Mühendisliği Bölümü, İstanbul, Türkiye (ORCID: 0000-0000-0000-0000)
}

(İlk Geliş Tarihi 28 Mayıs 2019 ve Kabul Tarihi 24 Temmuz 2019)

(DOI: 10.31590/ejosat.571167)

ATIF/REFERENCE: Yıldız A. \& Arıkan O. (2019). DC Elektrikli Raylı Sistemler İçin Teknik ve Ekonomik Açıdan Verimlilik Analizi. Avrupa Bilim ve Teknoloji Dergisi, (16), 729-739.

$\ddot{O} \mathbf{z}$

Elektrik enerjisinin kullanıldığı bütün sistemlerde enerji verimliliği çalışmaları yaygınlaşmaktadır. Bu durum büyük güç gerektiren raylı toplu taşıma sistemlerinde de önem arz etmektedir. Özellikle, mega kentlerde kullanılan metro ve tramvayların elektrik tüketimi azımsanmayacak seviyelere ulaşmaktadır. Örneğin İstanbul raylı toplu taşıma sistemi, yılda yaklaşık 300 milyon kWh enerji tüketmektedir. Tüketilen enerji dağılımları tramvay ve metro hatlarında farklılık göstermektedir. Tüketilen enerji miktarları dikkate alındığında, enerji verimliliğini arttırma çalışmalarının sağlayacağı teknik ve ekonomik faydalar daha da anlamlı hale gelmektedir.

Bu çalışmada, İstanbul şehir içi raylı ulaşım sisteminden seçilen örnek bir bölge için DC yük akışı analizleri gerçekleştirilmiştir. RAILSIM yazılımı kullanılarak yapılan modelleme ile hat paralelleme ve tren yüküne bağlı olarak teknik ve ekonomik değerlendirmeler gerçekleştirilmiştir. Farklı çalışma durumları için gerçekleştirilen teknik ve ekonomik verimlilik analizlerinden elde edilen sonuçların etkileri sunulmuştur.

Anahtar Kelimeler: Raylı sistemler, Enerji verimliliği, RAILSIM, DC yük akış analizi.

\section{Technical And Ecenomical Efficiency Analysis For DC Electric Railway Systems}

\begin{abstract}
Energy efficiency studies are becoming widespread in all systems where electrical energy is used. This situation is also important in rail public transportation systems that require great power. In particular, the electricity consumption of subway and trams used in mega-cities reaches a considerable level. For example, Istanbul urban public transportation system consumes about 300 million kWh of energy per year. The energy distribution consumed differs in tram and subway lines. Taking into account the amount of energy consumed, the technical and economic benefits of the efforts to increase energy efficiency are becoming more significant.

In this study, DC load flow analysis was performed for a sample area selected from the Istanbul urban public transportation system. Technical and economic evaluations have been carried out by modeling using RAILSIM software, depending on line parallelism and train load. The effects of the results obtained from technical and economic efficiency analyzes for different working situations are presented.
\end{abstract}

\footnotetext{
${ }^{1}$ Sorumlu Yazar: Yıldız Teknik Üniversitesi, Elektrik-Elektronik Fakültesi, Elektrik Mühendisliği Bölümü, İstanbul, Türkiye, ORCID: 0000-00000000-0000, ahmetyldz91@gmail.com
} 
Keywords: Railway systems, Energy efficiency, RAILSIM, CD load flow analysis.

\section{Giriş}

Günümüzün modern şehircilik anlayışında, özellikle büyük kentlerdeki nüfus yoğunluğu nedeniyle ulaşım önemli bir problem olmaya başlamıştır. Bu nedenle alternatif çözüm yolları aranmaktadır. Merkezi ve Yerel yönetimler yeni ulaşım planları düzenleyerek toplu taşımayı teşvik etmektedirler. Toplu taşıma denilince akla ilk gelen konvansiyonel taşıtlar modern şehircilik anlayışıyla yerini daha konforlu, verimli, ekonomik ve entegre olan raylı sistemlere bırakmaktadır. Metropollerde kent içi raylı sistemler hız, konfor, güvenilirlik ve çevre dostu oluşlarıyla büyük şehirlerin vazgeçilmezi olmalarıyla birlikte, sundukları yüksek taşıma kapasitesi ile de ön plana çıkmaktadırlar.

Raylı sistemlerde elektrik güç talebi ve enerji tüketimi sabit olmayıp, zamana, ağ içinde çalışan trenlere, yolcu sayısına ve iletişim sistemlerine bağlı olarak sürekli değişmektedir. Raylı sistemi oluşturan tüm alt sistemlerin etkileşimleri karmaşık olduğundan enerji tüketimlerini öngörmek ve değerlendirmek zordur. Bu nedenle, enerji verimliliğini iyileştirmek, detaylı çalışmaların yapılması, uygun yöntemlerin kullanılması ve elde edilen sonuçların hassas analizlerinin gerçekleştirilmesi ile mümkün olabilmektedir.

1990’lardan itibaren tüm dünyada ve ülkemizde kullanımı yaygınlaşan raylı toplu taşıma sistemlerinde enerji iletim sistemleri ve gerilim seviyeleri çeşitlilik göstermektedir. Ülkemizde yaygın olarak kullanılan gerilim seviyeleri, $34,5 \mathrm{kV} / 580 \mathrm{~V}$ AC cer transformatörü çıkışından doğrultucu grubuna gönderilerek $750 \mathrm{~V}$ DC ve 34,5/1200 V AC cer transfirmatörü çıkışından 1500 V DC elde edilerek kullanılan gerilim seviyeleridir. Genelde, her transformatör merkezinde çift cer ve iç ihtiyaç transformatörleri ile işletme sağlanmaktadır. Büyük güç gerektiren raylı ulaşım sistemlerinde yapılacak küçük bir verimlilik çalışmasının bile maddi karşılığının yansıması azımsanmayacak seviyede olacağından işletmesel açıdan optimizasyon çalışmalarının yapılması büyük önem arz etmektedir.

İstanbul, nüfus, kent içi ulaşım sistemi ve enerji tüketimi açısından önemli bir merkez olarak karşımıza çıkmaktadır. 154,25 kilometre uzunluğa sahip İstanbul, raylı toplu taşıma sistemi, yılda yaklaşık 300 milyon $\mathrm{kWh}$ enerji tüketmektedir. Tüketilen enerji dağılımları, metro hatlarında $\% 45$ 'i trenlerin hareketi $\% 55$ 'i de iç ihtiyacı karşılamak amacıyla kullanılırken, tramvay gibi yer üstünden giden raylı ulaşım sistemler için bu durum $\% 95$ 'i trenlerin hareketi $\% 5$ 'i de iç ihtyaç için kullanılmaktadır. Hızla inşaatı devam eden raylı sistemlerle birlikte 2023 sonrası nihai hedefte İstanbul raylı toplu taşıma sistemi hat uzunluğunun 1000 kilometreye yaklaşması beklenmektedir.

Ulaşım sektörü gelişen ve gelişmekte olan ülkelerde en çok enerji tüketen ve çevreyi kirleten işletmelerden biridir. Örneğin, Avrupa Birliği'nde toplam sera gazı emisyonlarının yaklaşık \%31'ine neden olmaktadır. Bu sektör içinde Büyükşehir taşımacılığı toplam $\mathrm{CO}_{2}$ emisyonlarının yaklaşık \%25'inden sorumludur [1]. Buna ek olarak yüksek hava kirliliği ve trafik sıkışıklı̆g kentsel alanlardaki ulaşım ile ilgili önemli konulardır. Raylı ulaşım sistemlerine, yüksek taşıma kapasitesi, güvenilirliği, yerel emisyonlarının olmaması ve metropol ulaşımının trafik etkisini azaltma potansiyeline sahip olması sebebiyle giderek daha fazla ilgi duyulmaktadır [2-3].

Günümüzde önemi giderek artan enerji verimliliği çalışmalarına paralel olarak, şehir içi raylı sistemlerde de gerekli teknik ve ekonomik analizlerin yapılması büyük önem arz etmektedir. Uluslararası Toplu Taşımacılar Birliği (International Associaton of Public Transport, UITP) ve Uluslararası Demiryolları Birliği (International Railways Associaton, UIC) son zamanlarda bu çalışmaları gündeme getirmiş ve bir standardizasyon oluşturmayı amaçlamıştır. Bununla birlikte, artan kapasite talepleri ve yükselen enerji maliyetleri bağlamında diğer ulaşım türlerinin çevresel performanslarını önemli ölçüde iyileştirdiği bir ortamda, şehir içi demiryolu, hizmet kalitesini etkilemeksizin enerji kullanımını en aza indirgemelidir.

Kentsel raylı sistemlerde enerji verimliliği çalışmaları, frenleme enerjisinin geri kazanılması, enerji depolama sistemleri, enerji tasarruflu sürüş yöntemleri, enerji verimli cer sistemleri, optimum trenler arası süre (Headway Time), hattın işletmesel açıdan yeniden yapılandırarak optimize edilmesi, hız ayarlaması vb. üzerine yoğunlaşmaktadır.

Regina Lamedica ve arkadaşları tarafindan yapılan bir projede, hat ve transformatör kapasitesinden daha yüksek bir başlangıç gücüne sahip trenlerin çalışmasına olanak sunan, batarya tabanlı enerji depolama sistemi ile donatılmış bir yardımcı transformatör merkezi (ABS, Auxiliary Battery Substation) temelli, yenilikçi bir çözüm önerilmektedir. Önerilen bu çözümün, hat üzerindeki tepe akım değerini ve gerilim düşüşlerinin etkisini azaltabileceği görülmüştür. Ayrıca, ABS yapısının demiryolu besleme hattındaki kayıpları azaltmaya ve enerji tasarrufunu arttırmaya olanak tanıdığı belirlenmiştir. Önerilen ABS ile gerçekleştirilen çalışmada, daha dengeli bir hat elde edildiği, ana transformatörden çekilen akımın tepe değerinde $\% 43,2$ 'lik azalma sağlandığı görülmüştür. Ayrıca, hat gerilim düşümünün $\% 5,26$ ve kayıpların ise $\% 22,4$ oranında azaldığı tespit edilmiştir [4].

Otomatik Sürüş sistemleri günümüzde birçok yeni hatta uygulanmaktadır. Otomatik sürüşün avantajı manuel sürüşteki makinist ve işletme hatalarının en düşük seviyeye indirilmesidir [5]. Modern sistemlerde maksimum hızı artırma ve sonrasında boşta gitme (coasting) moduna geçilmesi ile daha fazla enerji tasarrufu sağlanabileceği belirtilmektedir [5]. Birçok bilim insanı çekiş enerji tüketimini azaltmak için enerji tasarrufu sağlayan tren kontrolü üzerinde çalışmışlardır. Chang, dakiklik, sürüş konforu ve enerji tüketimi gereksinimlerini karşılamak için optimize edilmiş süzülme kontrolü uygulayarak tren operasyonlarını optimize etmek için genetik algoritma kullanmıştır [6]. Howlett, sürekli tren kontrolü problemi için optimal anahtarlama noktalarını bulmak amacıyla Pontryagin ilkesini kullanmıştır. Ayrıca, ayrık kontrol problemindeki her sabit kontrol dizisi için yakıt maliyetini en aza indirmek amacıyla en uygun anahtarlama zamanlarını elde etmiştir [7]. Ke, enerji tüketimini en aza indirgemek için kombinatoryal bir 
optimizasyon modeli önermiş ve enerji tasarrufu sağlamak amacıyla tren hız yörüngesini optimize etmek için karınca kolonisi optimizasyon algoritmalarının MAX-MIN ant sistemini kullanmıştır [8].

Hızlanma profilleri ve maksimum hız limitleri demiryolu hizmetlerinde cer enerji tüketimini belirleyen kritik faktörlerdir. Bu nedenle, emniyet ve zamanlama kısıtlamaları dahilinde, hız optimizasyonu önemli enerji tasarruflarını sağlayabilmektedir. Örneğin, yolculuk uzunluğundaki artışı telafi etmek için ek bir tren gerekli olmasına rağmen, Brüksel metro hattındaki hız sınırlarının (72 $\mathrm{km} / \mathrm{sa}$ ' den $60 \mathrm{~km} / \mathrm{sa}$ 'e ve $60 \mathrm{~km} / \mathrm{sa}$ 'den $50 \mathrm{~km} / \mathrm{sa}$ 'e) yeniden ayarlanması $\% 15$ cer enerji tasarrufu ile sonuçlanmıştır. Optimum süzülme noktalarını ve hız profillerini belirlemek için literatürde farklı metodolojiler önerilmiştir [9-10]. Bunlar,

- Optimum enerji tasarrufu için belirlenecek hız profilinin temel özellikleri,

- Yüksek başlangıç ivmesi,

- İstasyonlar arası mesafeyi, yolcu yoğunluğunu, zaman çizelgesini ve hat geometrisini göze alarak en uygun düşük boşa alma hizı,

- Uzun boşta gitme süresi,

- Yüksek frenleme ivmesi,

- Düşük bekleme süresi,

olarak sıralanabilir. Bu konu ile ilgili çalışmalar incelendiğinde, işletmede \%20-30 arasında enerji tasarrufu sağlanabildiği anlaşılmaktadır [11].

Raylı ulaşım sistemlerindeki aktif güç kayıpları, akımın karesi ile orantılıdır. Bu nedenle, ağdaki farklı trenlerin aynı anda hızlanmasından kaynaklanan yüksek güç değerleri (yüksek akımlar) sınırlanarak, kayıplar önemli ölçüde azaltılabilir. Kayıpları azaltmak için birbaşka seçenek ise besleme hatları için düşük dirençli malzemeler kullanmaktır. Nispeten yüksek yatırım maliyetleri gerektirmesine rağmen, üçüncü ray beslemeli güç sistemlerinin, standart çelik iletken raylar yerine \%50 daha az dirence sahip aluminyum esaslı raylarla değiştirilerek iletim kayıpları azaltılabilmektedir [12]

Raylı sistemlerde kullanılan aracın hızı, istenilen hıza ulaşmak için ivmelenmesi sebebiyle kütlesi enerji tüketimi üzerinde büyük etkiye sahiptir. Tren kütlesindeki \%10 oranda bir artış, araç enerji tüketiminin \%6-8 oranında artmasına sebebiyet vermektedir [13]. Ayrıca, demiryolu aracının kütlesinin azaltılması yola daha az zarar verir, tekerleklerin ve frenin aşınmasını azaltır. Bu nedenle sistemin işletme ve bakım masraflarını düşürür [14].

Hatların paralellenmesi akım bölüşümünü artırarak sistemin rahatlamasını ve enerji kayıplarının azaltmasını sağlamaktdır. Açıkbaş ve Söylemez tarafından gerçekleştirilen çalışmada, farklı çalışma senaryoları için elde edilen enerji tasarrufu bilgileri verilmiştir [15]. Gerilim değişiminin enerji tasarrufuna etkileri çeşitli çalışmalarda incelenmişstir. Açıkbaş’ın SimuX programı kullanarak yaptığı çalışmasında $750 \mathrm{~V}$ DC ile $1500 \mathrm{~V} \mathrm{DC}$ besleme sistemlerini çeşitli parametreleri dikkate alarak karşılaştırmıştır. Sonuç olarak, 1500 V DC sistemin 750 V DC sistem üzerinde birçok avantajı olduğunu belirtmiştir. Açıkbaş'1n İstanbul'un Anadolu yakasında yapılması planlanan Üsküdar-Ümraniye Metro hattına ilişkin veriler ile yapmış olduğu bu çalışmada besleme sisteminin 750 V DC yerine 1500 V DC seçilmesi durumunda elde edilecek tasarrufun \%10 mertebelerinde olacağı belirlenmiştir [16].

Raylı ulaşım sistemi istasyonları ve özellikle de metro istasyonları, yolcu hareketliliği ile ticari hizmetleri birleştiren ve yolcu konforunun büyük önem taşıdığı komplike sistemlerdir. Enerji tüketimi HVAC (Heating, Ventilating, Air Conditioning, Cooling; Isıtma, Havalandırma, İklimlendirme, Soğutma) aydınlatma, yürüyen merdivenler, hareketli yürüyüş yolları ve bilgi reklam ekranlarını içermektedir [17]. Aydınlatmada enerji tasarrufuna yönelik olarak daha verimli lambaların tanıtımıyla önemli enerji tasarrufu sağlanabilir. Bielefeld ve Hon Kong metro istasyonlarında mevcut lambaları floresan ve led lambalarla değiştirerek sırasıyla, floresan lamba kullanma durumunda \%32 ve led kullanma durumunda ise \%40’lık bir enerji tasarrufu sağlanmıştır [1]. Ayrıca aydınlık yoğunluğunun otomatik olarak ayarlanması (trenler çalışmadığı saatlerde otomatik olarak kapatılması) da kayda değer enerji tasarrufu sağlayabilmektedir. Sonuç olarak, istasyonlarda enerji tasarrufu, tüm alt sistemlerinin entegreli yönetimi ile en üst düzeye çıkarılabilir. Bu nedenle, HVAC, aydınlatma ve yolcu konveyör sistemlerine adaptif kontrol stratejileri toplu olarak uygulandığında metro istasyonlarının enerji tüketiminde \% 5-10'luk bir azalma beklenebilir [18].

Yasin Sarıkavak'ın çalışmasında, Shift2Rail kamu ve özel sektör ortaklarının dahil olduğu geleceğin demiryolu sistemlerinin inşasına odaklanmış bir Avrupa Birliği programından bahsetmiştir. Bu program sayesinde maliyet açısından verimli, güvenilir, yüksek kapasiteli ve yüksek hılı trenlerin üretilmesi hedeflenmektedir. Bu teknolojilerin uzun vadeli sonuçları olarak, demiryolu sistemlerinde yolcu konforunun iyileştirilmesi dışında, \%15 kapasite artış1, işletme güvenliği ve zamanında ulaşım konusunda \%50 iyileşme, sistemlerin enerji verimliliği konusunda \%30 iyileşme, araç ve hat bakım maliyetlerinde \%40 düşüş beklenmektedir [19].

$\mathrm{Bu}$ çalışmada, İstanbul metrosundan seçilen örnek bir hat RAILSIM yazılımında modellenmiştir. Bu modelde, ilk olarak katener hatlarının farklı sıklıklarda paralellenmesinin enerji tüketimi üzerine etkisi simüle edilmiş ve sonuçları paylaşılmıştır. İkinci olarak, farklı yolcu sayısındaki trenler simülasyon programında çalıştırılarak tren ağırlığı değişimlerinin hattın güç tüketimi ve gerilim seviyesi üzerindeki etkileri incelenmiştir. Ayrıca, kişi (yolcu) başına düşen enerji tüketimleri de yorumlanmıştır. Sonuçların daha iyi anlaşılabilmesi açısından katener hatlarının paralellenmesi ve tren ağırlık değişiminin simülasyon çıktıları üzerinden maliyet analizi çalışmaları yapılmış ve elde edilen sonuçlar sunulmuştur.

\section{Sistem Tanıtımı}

İstanbul metro sisteminden örnek olarak seçilen 26,8 km'lik bir hat RAILSIM programında DC yük akış analizi gerçekleştirilmek üzere modellenmiştir. $\mathrm{Bu}$ hat, ray, eğim, viraj ve elektrifikasyon bilgileri açısından gerçek verileri ile modellenmiştir. $750 \mathrm{~V}$ DC 
gerilim seviyesinde katener hattı üzerinden beslenen hatta 18 istasyon bulunmaktadır. Seçilen hat üzerinde çalışan $92,8 \mathrm{~m}$ uzunluğunda 4 vagonlu 1998 model Alstom araçları RAILSIM programında modellenerek gerçeğe yakın analizler yapılmıştır.

\subsection{Hat Tanitımı}

Seçilen hattın elektrifikasyon sistemini, 12 adet transformatör merkezi, 5 adet indirici merkez ve transformatör merkezileri arasında bulunan orta gerilim kabloları oluşturmaktadır. İncelenen sistemin basitleştirilmiş tek hat şeması Şekil 2.1'de verilmiştir.

\section{Şekil 2.1. Hattın Basitleştirilmiş Tek Hat Şeması}

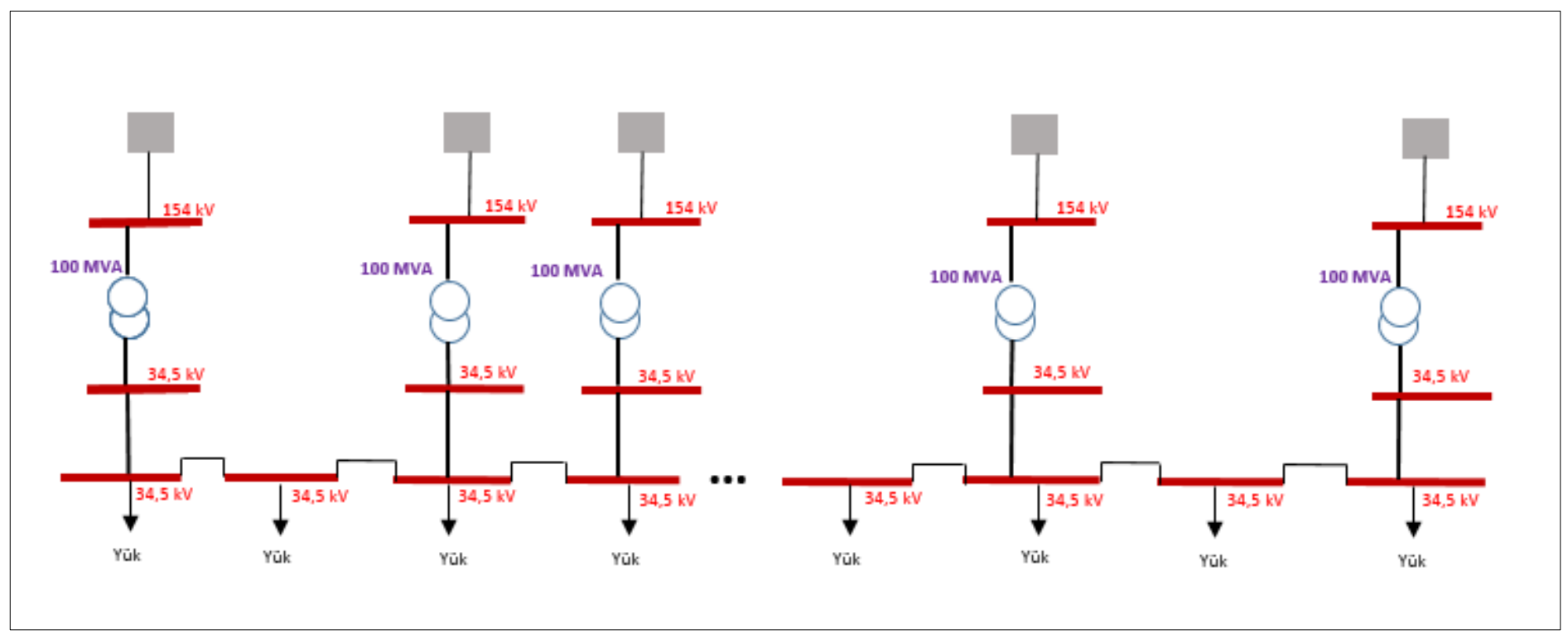

İncelenen hat 26,8 km olup toplam 18 adet istasyon bulunmaktadır. Bunlardan 7 tanesi tünel, 3 tanesi viyadük ve 8 tanesi de yer üstü tipi istasyonlardır. İstasyonlar arası elektrifikasyon bağlantısı $3 \times\left[3 \times\left(1 \times 240 \mathrm{~mm}^{2}\right)\right]$ kesitli OG kablolar ile sağlanmaktadır. Çalışmada, geliş ve gidiş katener hatları arasında belirli noktalarda her $2000 \mathrm{~m}$ (17 adet), $1000 \mathrm{~m}$ (30 adet) ve $250 \mathrm{~m}$ 'de bir (129 adet) $1 \times 120 \mathrm{~mm}^{2}$ kesitli OG kablolarıyla paralelleme yapılmış ve sonuçları paylaşılmıştır.

\subsection{Elektrifikasyon Sistemi}

Metro hattının OG elektrifikasyon sistemini, incelenen hat üzerinde bulunan 12 adet transformatör merkezi, 5 adet indirici merkez ve transformatör merkezleri arasında bulunan orta gerilim kabloları oluşturmaktadır. Ayrıca, elektrifikasyon sistemini oluşturan transformatör merkezlerinin basitleştirilmiş şeması Şekil 2. 2'de gösterilmiştir. Şemadan da görüldüğü gibi OG ring hattı üzerinden gelen enerji, OG kesicisinden geçerek cer transformatörlerine iletilmektedir. Burada, $580 \mathrm{~V}$ AC gerilim seviyesine düşürülerek 12 darbeli doğrultucu gurubuna girer, $750 \mathrm{~V}$ DC gerilim seviyesinde katener hattı üzerinden araç pantografina iletilir ve ray hattı üzerinden geri dönerek devresini tamamlamı̧s olur.

Şekil 2.2. Raylı Sistem Elektrifikasyon Örneği

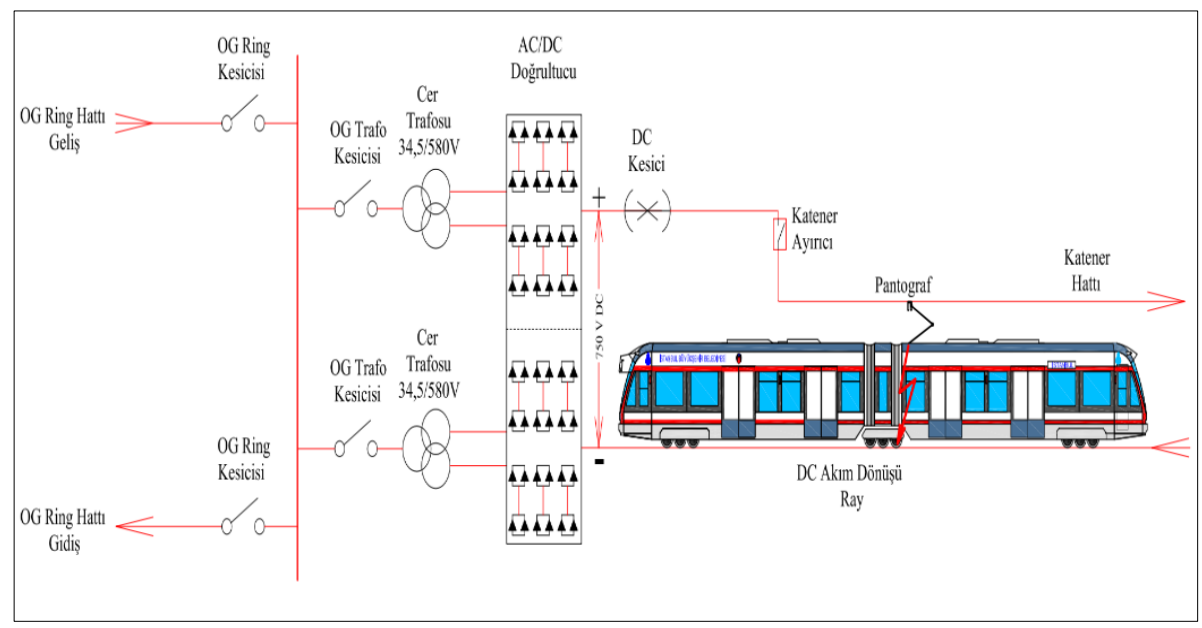

\subsection{Transforamtör Merkezleri}


Simülasyonu yapılan hatta bulunan toplam 18 adet istasyon ve $26,8 \mathrm{~km}$ uzunluğundaki katener hattının enerji beslenmesi hat üzerinde çeşitli lokasyonlarda kurulu olan toplam 12 adet transformatör merkezi ile sağlanmaktadır. Transformatör merkezlerinde $34,5 \mathrm{kV}$ AC orta gerilim baralar bulunmakta olup, transformatör merkezleri birbirlerine orta gerilim enerji kabloları üzerinden bağlanarak ring şebeke oluşturmaktadır. Olușturulan ring şebeke sayesinde herhangi bir TEİAŞ 154 / 34,5 kV giriş beslemesinde meydana gelen bir enerji kesintisinde ring kesici hücreleri ile manevra yapılarak bir başka indirici merkezden enerji beslemesi sağlanmaktadır.

Transformatör merkezleri ve TEİAŞ indirici merkezlerine basit gösterim için kodlar verilmiştir. Sistemin numaralandırılmış şemas1 Şekil 2.3'de verilmiştir;

\section{Şekil 2.3. Hattın Orta Gerilim Sisteminin Basitleştirilmiş Diyagramı}

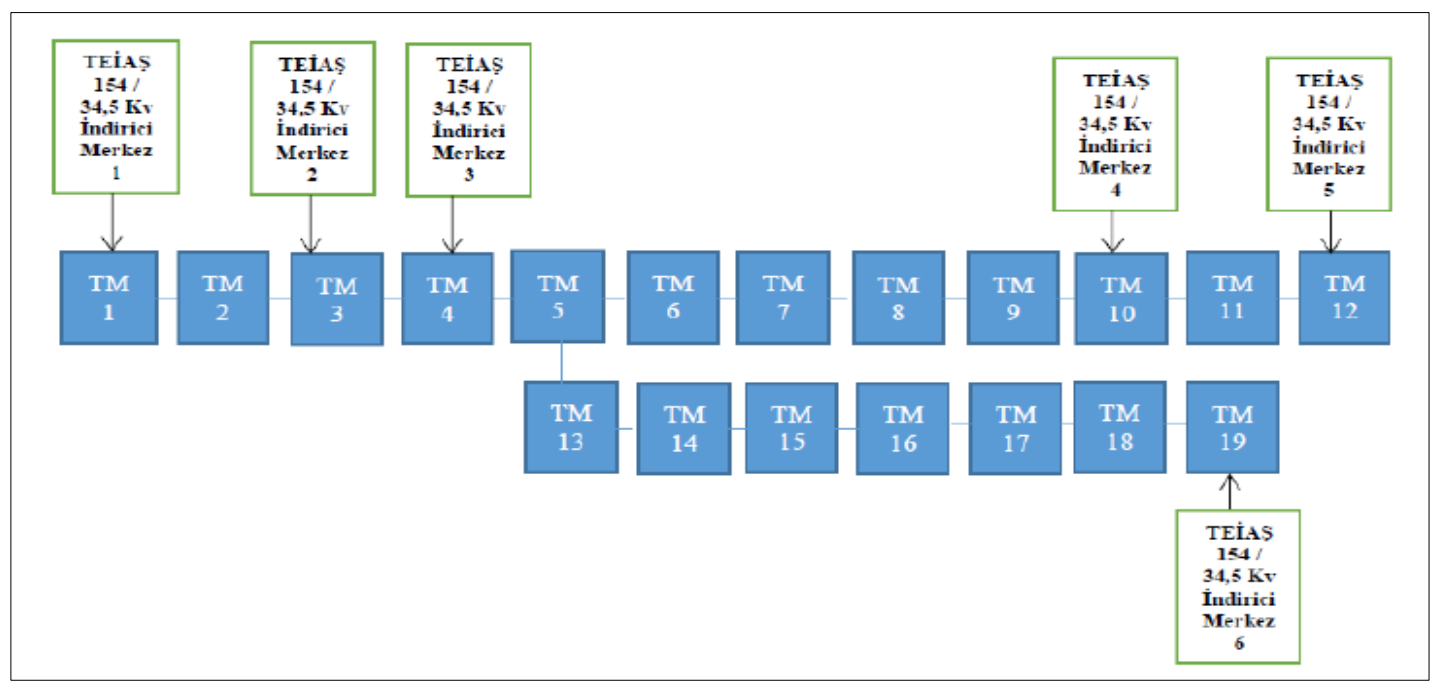

Şekil 2.4’te görüldüğü gibi çift sekonderli cer transformatörleri $34,5 \mathrm{kV}$ gerilimi $580 \mathrm{~V}$ AC gerilim dönüştürürek doğrultucu merkezine iletilir. Buradan $750 \mathrm{~V}$ DC gerilime dönüştürülerek katener hattına verilir. İç ihtiyaç transformatörleri ise istasyonda bulunan tüm (cer dışında) yükleri beslemektedir.

Şekil 2.4. Örnek Bir Transformatör Merkezi Açık Şeması

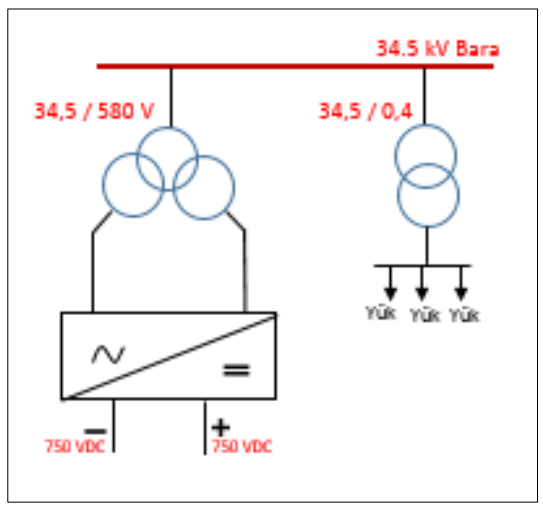

\section{Modelleme ve Analiz Çalışmaları}

Modelleme ve analiz çalışmalarında İstanbul raylı ulaşım sisteminden örnek olarak alınan bir hat kullanılmıştır. Seçilen bu hat üzerinde RAILSIM programı ile DC yük akış analizi gerçekleştirilmiştir. Ray, eğim, viraj ve elektrifikasyon bilgileri açısından gerçek veriler ile modellenmiştir.

Seçilen metro hattında tek bir tren hareketine ait veriler DC Simülasyon programı RAILSIM vasıtası ile irdelenmiştir. Simülasyon çalı̧̧masında 4 vagonlu İstanbul Ulaşım 1988 ABB Hafif Metro aracı olarak tek bir tren, seçilen güzergah ve doğrultu boyunca çalıştırılarak yük akışı analizi yapılmıştır. Tren performans bilgileri farklı çalışma koşullarında elde edilmiş ve enerji verimliliğine olan etkileri gösterilmiştir. Simülasyon ortamında tren aracı, Şekil 2.3’te verilen sistemde görülen TM1-TM12 transformatör merkezleri arasındaki güzergahta bulunan 18 istasyon arasında hareket ettirilmiştir. Hattın yapısına göre TM13 transformatör merkezinin bulunduğu istasyonda yol ayrımı bulunmakta olup, farklı bir hat olarak çalışmaktadır. TM13-TM19 transformatör merkezleri hattın bu bölümünü beslemekle beraber, analizi gerçekleştirilen TM1-TM12 arası güzergahın enerjilendirilmesine de az da olsa katk1 sağlamaktadır. Bu nedenle, simülasyon çalışmalarında TM13-TM19 transformatör merkezlerinin katkıları da dikkate alınarak modele yansıltılmıştır. 
Senaryolardan birincisi, katener hatlarının farklı sıklıklarda paralellenmesinin enerji tüketimi üzerine etkisinin incelenmesidir. İkinici senaryo ise, tren ağırlık değişiminin enerji tüketimi üzerine etkisi ve yolcu başına düşen enerji maliyetinin irdelenmesi olmuştur. Son olarak her iki senaryoya ait maliyet analizleri yapılarak elde edilen bulgular sunulmuştur.

\subsection{Senaryo 1: Katener Hatlarının Paralellenmesi (Jumper-Atlama Kabloları)}

DC gerilim ile beslenen çift hatlı sistemlerde her iki hatta ait katener sistemleri yalıtılmış kablolar ile paralellenebilmektedir. Görselliğinin yanı sıra paralelleme aynı zamanda enerji tasarrufu ve gerilim dengelemesi de sağlamaktadır. Hatların paralellemesi, akım bölüşümünü artırarak sistemin yüklenmesini hafifletmesi ve enerji kayıplarını azaltması gibi avantajlara sahiptir.

Bu çalışmada, 4 vagonlu Alstom aracı boş olarak, modellenen hat üzerinde, katener hatları arasında herhangi bir paralelleme yapılmaması, hattın mevcut durumu (13 adet jumper), her 2000 metrede, 1000 metrede ve 250 metrede bir jumper (atlama kabloları) ile katener hatlarının birbirine bağlanması durumlarında modelleme ve analizler yapılarak sistemden çekilen güç ve akım değerleri karşılaştırılmıştır.

\subsubsection{Güç Tüketim Üzerindeki Etkiler}

RAILSIM yazılımında oluşturulan modelde, trenin hareketi boyunca her 2 sn'de bir alınan güç çıkış değerleri ile RMS (Root Mean Square) güç hesaplanmıştır. Gerçekleştirilen simülasyonlar sonucu Tablo 3. 1'de görüldüğü gibi katener hatları arasında jumperlama sıklığı arttıkça tren tarafından çekilen toplam gücün azaldığı görülmektedir.

Tablo 3. 1 Tüm TM’lerin RMS Güç Değerleri Sonuçları

\begin{tabular}{|c|c|c|c|c|c|}
\hline 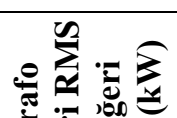 & $\begin{array}{c}\text { Jumper } \\
\text { Yok }\end{array}$ & $\begin{array}{l}\text { Mevcut } \\
\text { Durum }\end{array}$ & $2000 \mathrm{~m}$ & $1000 \mathrm{~m}$ & $250 \mathrm{~m}$ \\
\hline 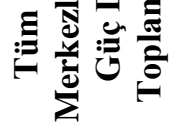 & 789,28 & 776,6 & 776,19 & 754,39 & 734,46 \\
\hline
\end{tabular}

Modellenen hat boyunca katener hatları arasında paralelleme olmadığı durumda çekilen güç değeri 789,28 kW iken, her 250 metrede bir paralelleme olduğu durumda bu değer yaklaşık \%6,95'lik bir azalma ile 734,46 kW'a düşmüştür.

\subsection{2. Çekilen Akım Üzerindeki Etkiler}

RAILSIM yazılımda gerçekleştirilen simülasyonlar sonucu tüm transformatör merkezlerinden çekilen akımların RMS değeri ve maksimum akımların ortalaması Tablo 3.2'de paylaşılmışıtır.

Tablo 3. 2 Tüm TM’lerin RMS Akım Değerleri Sonuçları

\begin{tabular}{|c|c|c|c|c|}
\hline Seçilen Hattın Jumper Durumu & $\begin{array}{c}\text { Jumper } \\
\text { Yok }\end{array}$ & $\mathbf{2 0 0 0 ~} \mathbf{~ m}$ & $\mathbf{1 0 0 0} \mathbf{~ m}$ & $\mathbf{2 5 0} \mathbf{~ m}$ \\
\hline $\begin{array}{c}\text { Tüm Trafo Merkezleri RMS } \\
\text { Akım Değeri (A) }\end{array}$ & 103,73 & 103,93 & 100,94 & 98,04 \\
\hline $\begin{array}{c}\text { Tüm Trafo Merkezleri Ortalama } \\
\text { Maks. Akım Değeri (A) }\end{array}$ & 592,34 & 580,07 & 547,42 & 518,19 \\
\hline
\end{tabular}

Elde edilen sonuçlara göre çekilen maksimum akımların ortalama değeri hatlar arasında paralelleme olmadı̆̆ durumda 592,34 A iken her 250 metrede bir paralelleme yapıldığında \%12,52'lik bir azalma ile 518,19 A'e düşmüştür. Çekilen maksimum akımın, katener hatları arasında atlama kabloları kullanarak sınırlanabileceği görülmüştür. Efektif akım (RMS) değerinin ise 103,73 A den \%5,48'lik bir azalma ile 98,04 A değerine düştüğü belirlenmiştir.

\subsubsection{Paralellemenin Hat Gerilimi (Trenin Pantografinın Ucundan Okunan Gerilim) Üzerindeki Etkisinin Incelenmesi}

Paralelleme kablolarının sıklığının artırılması hattın toplam empedansını (direncini) düşürdüğü için hattaki gerilim düşümünü de azaltmaktadır. Bu sebepten dolayı transformatör noktaları arasındaki mesafeyi artırarak daha az sayıda transformatör merkezi kurarak işletmenin sağlanması mümkün olmaktadır.

Tablo 3. 3 Tren Pantografinın Ucundan Okunan Minimum Gerilim Değerleri

\begin{tabular}{|c|c|c|c|c|}
\hline \multicolumn{5}{|c|}{ Hattaki Minimum Gerilim (V) } \\
\hline Jumper Yok & Mevcut Durum & $\mathbf{2 0 0 0} \mathbf{~ m}$ & $\mathbf{1 0 0 0} \mathbf{~ m}$ & $\mathbf{2 5 0} \mathbf{~ m}$ \\
\hline 696,41 & 709,96 & 701,62 & 759,26 & 774,34 \\
\hline
\end{tabular}


Tablo 3. 3 'te modellenen hat boyunca trenin pantografının katener hattı ile temas ettiği noktadan okunan en düşük gerilim seviyeleri görülmektedir. Simülasyon sonuçlarına göre hatların paralellenmesi gerilim düşümünü azaltmaktadır. 250 metrede bir paralleme yapılması durumunda gerilim düşümü, hatların hiç paralellenmemesi durumuna kıyasla \%10,06 oranında azalmıştır.

\subsection{Senaryo 2: Trenin Toplam Kütle Artışının Enerji Tüketimi Üzerine Etkisi}

Hafif olan araçlar ağır olanlara göre, ilerlemeye karşı daha düşük mekanik direnç gösterir ve aynı performans seviyesine ulaşmak için daha az kinetik enerji gerektirir. Bu nedenle, raylı taşııın toplam kütlesinin en aza indirilmesi, cer enerji tüketimini azaltmaktadır.

Araç ağırlığının enerji tüketimine etkisini göstermek amacıyla, aynı tren aracı kullanılarak incelenen hattın istasyonları arasında,

- Boş,

- 300 yolcu,

- 600 yolcu,

- 900 yolcu,

- 1200 yolcu,

bulunması durumları için simülasyonlar gerçekleştirilmiş ve elde edilen sonuçlar Tablo 3. 4 'te verilmiştir. Simülasyonlarda ortalama yolcu ağırlığ $75 \mathrm{~kg}$ olarak alınmıştır. İstasyonlarda beklemeli $(20 \mathrm{~s})$ ve beklemesiz olmak üzere iki farklı çalışmaya göre sonuçlar elde edilmiştir.

Tablo 3. 4 Tren Kütle Artışının Enerji Tüketimine Etkisi

\begin{tabular}{|c|c|c|c|c|c|c|c|c|c|c|}
\hline \multirow[b]{2}{*}{$\begin{array}{l}\text { Çalışma } \\
\text { Durumu }\end{array}$} & \multicolumn{2}{|c|}{ Boş } & \multicolumn{2}{|c|}{300 Kişi } & \multicolumn{2}{|c|}{600 Kişi } & \multicolumn{2}{|c|}{900 Kişi } & \multicolumn{2}{|c|}{1200 Kişi } \\
\hline & $\mid \begin{array}{c}\text { Beklemeli 20 } \\
\text { sn }\end{array}$ & Beklemesiz & $\begin{array}{l}\text { Beklemeli } \\
20 \mathrm{sn}\end{array}$ & Beklemesiz & $\begin{array}{c}\text { Beklemeli } 20 \\
\text { sn }\end{array}$ & Beklemesiz & $\begin{array}{l}\text { Beklemeli } \\
20 \mathrm{sn}\end{array}$ & Beklemesiz & $\begin{array}{l}\text { Beklemeli } \\
20 \mathrm{sn}\end{array}$ & Beklemesiz \\
\hline $\begin{array}{c}\text { Tren } \\
\text { Ağırlığı } \\
(\mathbf{K g})\end{array}$ & \multicolumn{2}{|c|}{119747,76} & \multicolumn{2}{|c|}{142247,82} & \multicolumn{2}{|c|}{164747,88} & \multicolumn{2}{|c|}{187247,76} & \multicolumn{2}{|c|}{209748} \\
\hline $\begin{array}{l}\text { Toplam } \\
\text { Süre }\end{array}$ & 00:28:46 & 00:23:26 & 00:29:12 & 00:23:52 & 00:29:46 & 00:24:26 & 00:30:13 & 00:24:53 & 00:30:40 & 00:25:20 \\
\hline $\begin{array}{c}\text { Ortalama } \\
\mathrm{Hiz}(\mathrm{km} / \mathrm{sa})\end{array}$ & 41,04 & 50,38 & 40,43 & 49,47 & 39,66 & 48,32 & 39,07 & 47,45 & 38,49 & 46,6 \\
\hline $\begin{array}{c}\text { Maks. Hiz } \\
(\mathbf{k m} / \mathbf{s a})\end{array}$ & 80 & 80 & 80 & 80 & 80 & 80 & 80 & 80 & 80 & 80 \\
\hline $\begin{array}{l}\text { Tepe Güç } \\
(\mathbf{k W})\end{array}$ & 2004,59 & 2004,59 & 2160,66 & 2160,66 & 2295,06 & 2295,06 & 2402,35 & 2402,35 & 2427,8 & 2427,8 \\
\hline $\begin{array}{c}\text { Harcanan } \\
\text { Enerji } \\
\text { (kWh) }\end{array}$ & 318,25974 & 303,9664 & 347,79778 & 333,50444 & 375,00335 & 360,71002 & 400,24946 & 385,95613 & 422,48408 & 408,19075 \\
\hline $\begin{array}{l}\text { Ortalama } \\
\text { Güç }(\mathbf{k W})\end{array}$ & 663,80942 & 778,29245 & 714,16381 & 837,95085 & 755,88582 & 885,78181 & 794,75899 & 930,63769 & 826,59946 & 966,77265 \\
\hline
\end{tabular}

Tablo 3. 4'ten de görüldüğü üzere tren toplam kütle artışının birçok durumu etkilediği gözlemlenmiştir. Aracın boş ağırlı̆ğ simülasyon programından $119.747,76 \mathrm{Kg}$ olarak alınmıştır.

Boşta çalışma ve 1200 kişilik tam dolu yolcu ile çalışma kıyaslandığında, tren toplam kütlesi yaklaşık \%75 artarken; enerji tüketimindeki artış beklemeli (with dwell) çalışma durumda \%32,74 iken, beklemesiz çalışma durumda \%34,28 olmuştur. Trenin yüksüz çalıştğ̆ durum ile tam yüklü olduğu durum arasında çekilen tepe güç değerleri karşılaştırılacak olursa, yüksüz çalıştığı durumda çekilen tepe güç değeri 2004,59 kW iken 1200 adet yolcu ile hareket ettiği durumda 2427,8 kW olarak elde edilmiştir. Buradan, tren kütlesindeki \% $75^{\prime}$ lik artışın çekilen tepe gücü \%21,11 oranında arttırdığı görülmüştür.

Enerji tüketimlerini daha iyi yorumlayabilmek için $\mathrm{kWh} /$ kişi başına düşen tüketim değerleri Tablo 3.5 'te verilmiştir.

Tablo 3. 5 kWh / kişi Başına Enerji Tüketim Değerleri

\begin{tabular}{|c|c|c|}
\cline { 2 - 3 } \multicolumn{1}{c|}{} & \multicolumn{2}{c|}{ Enerji Tüketimleri (kWh/Kişi) } \\
\hline \multirow{2}{*}{ Çalışma Durumu } & Beklemeli 20 sn & Beklemesiz \\
& & 1,111 \\
\hline 300 Yolculuk & 1,159 & 0,601 \\
\hline 600 Yolculuk & 0,625 & \\
\hline
\end{tabular}




\begin{tabular}{|c|c|c|}
$\mathbf{9 0 0}$ Yolculuk & 0,444 & 0,428 \\
\hline $\mathbf{1 2 0 0}$ Yolculuk & 0,352 & 0,34 \\
\hline
\end{tabular}

Doğal olarak trenlerin ağırlığı doluluk oranına bağlıdır. Tren içindeki seyehat eden yolcu sayısı arttıkça trenin ağırlığı ve dolayısıyla enerji tüketim miktarı artacaktır. Kişi başına düşen enerji tüketiminin etkisini araştırmak için tren farklı sayılarda yolcu ile doluyken ki durumların analizi yapılmıştır. Tablo 3.5 incelendiğinde trendeki yolcu sayısı arttıkça kişi başına düşen enerji tüketim değerinin azaldığı görülmektedir. Wh / kişi*km olarak enerji tüketim değerleri ise Tablo 3.6'da verilmiştir.

Tablo 3. $6 \mathrm{Wh} /$ kişi*km Başına Enerji Tüketim Değerleri

\begin{tabular}{|c|c|c|}
\cline { 2 - 3 } \multicolumn{1}{c|}{} & \multicolumn{2}{c|}{ Enerji Tüketimleri (Wh/Kişi $\left.{ }^{*} \mathbf{k m}\right)$} \\
\hline Çalş̧ma Durumu & Beklemeli 20 sn & Beklemesiz \\
\hline $\mathbf{3 0 0}$ Yolculuk & 58,92 & 56,5 \\
\hline $\mathbf{6 0 0}$ Yolculuk & 31,76 & 30,55 \\
\hline 900 Yolculuk & 22,6 & 21,79 \\
\hline $\mathbf{1 2 0 0}$ Yolculuk & 17,89 & 17,28 \\
\hline
\end{tabular}

Tablo 3.6'dan, bir km de kişi başına düşen enerji tüketimi, 300 yolculu hareket durumunda 56,5 Wh iken, 1200 yolculu durumda 17,28 Wh'e düştüğü görülmektedir.

\section{Maliyet Analizi}

$\mathrm{Bu}$ bölümde, incelenen hatta gerçekleştirilen senaryoların enerji tüketimine etkileri dikkate alınarak maliyet analizleri gerçekleştirilmiş̧ir. Analizlerde ihtiyaç duyulan yatırım maliyetleri de dikkate alınarak elde edilen sonuçlar sunulmuştur.

\subsection{Katener Hatlarının Paralellenmesi İçin Maliyet Analizi}

Katener hatları arasında atlama kabloları ile paralelleme yapılması durumunun maliyet açısından analizi gerçekleştirilmiştir. Hattın mevcut durumunda, bazı noktalarında paralelleme kabloları vardır. Bu kablolar, $1 \mathrm{kV}$ gerilim seviyesinde çift izoleli 1x120 $\mathrm{mm}^{2}$ kesitli bakır kablolardır. İncelenen farklı senaryolar için de bu tip kabloların kullanıldığı kabul edilmiştir. Tablo 4.1'de Ocak 2019 HES kablo kataloğundan alınan kablo birim fiyat değeri verilmiştir [20].

Tablo 4. 1 1x120 mm2 Bakır Kablo Fiyatı

\begin{tabular}{|c|c|}
\hline Kablo Kesiti & Birim Fyatı (\$)/m) \\
\hline $1 \times 120 \mathrm{~mm}^{2}$ Çift izoleli Bakır KABLO & 138,000 \\
\hline
\end{tabular}

Bir paralelleme kablosunun uzunluğu ortalama 8 m'dir. Kullanılan adet bilgileri Tablo 4.2'de verilmiştir.

Tablo 4. 2 Paralelleme Kablosu Adetleri

\begin{tabular}{|c|c|}
\hline \multicolumn{2}{|c|}{ Kuıllanılan Jumper Adetleri } \\
\hline Jumper Yok & 0 adet \\
\hline Mevcut Durum & 13 adet \\
\hline $2000 \mathrm{~m}$ & 17 adet \\
\hline $1000 \mathrm{~m}$ & 35 adet \\
\hline $250 \mathrm{~m}$ & 129 adet \\
\hline
\end{tabular}

Paralelleme kablolarının kurulum maliyeti, bir adetinin ortalama uzunluğu 8 metre kabul edilerek Tablo 4.1'de verilen birim fiyat üzerinden hesaplanmış ve Tablo 4.3 'te sunulmuştur.

Tablo 4. 3 Paralelleme Kablosu Kurulum Maliyeti

\begin{tabular}{|c|c|}
\hline \multicolumn{2}{|c|}{ Paralelleme Kablosu Kurulum Maliyetleri (六) } \\
\hline Jumper Yok & $0 €$ \\
\hline Mevcut Durum & $14.352,00 €$ \\
\hline $2000 \mathrm{~m}$ & $18.768,00 €$ \\
\hline $1000 \mathrm{~m}$ & $38.640,00 €$ \\
\hline $250 \mathrm{~m}$ & $142.416,00 €$ \\
\hline
\end{tabular}

Maliyet analizi gerçekleştirirken aşağıdaki koşullar dikkate alınmıştır. 
- Araçlar günde 18 saat çalışmaktadır.

- Enerji maliyeti yaklaşık 0,54€ / kWh üzerinden hesaplanmaktadır.

- Bir yıl 365 gün olarak alınmıştır.

Paralelleme yapılmadığı durum ile 2000 m'de bir yapıldığı durum analizi: Tablo 3.1'den parallelleme yapılmadığı durumda çekilen toplam güç 789,28 kW, 2000 m'de bir yapıldığı durumda ise 776,19 kW olarak verilmiştir. 2000 m'de bir paralelleme kablosu çekildiği durumda, hiç olmaması durumuna göre 13,09 kW'lık bir kazanç elde edileceği görülmektedir. Bu durumda günlük enerji kazancı ise $13,09 * 18=235,62 \mathrm{kWh}$ olmaktadır. Maddi açıdan sağlanan günlük kazanç değeri ise 235,62*0,54 = 127,234 € olarak hesaplanmıştır. Kablo maliyetinin karşılanma süresi ise yaklaşık 148 gündür. Bir yılın sonunda sağlanan toplam kazanç 46.440,41 olarak hesaplanmıştır. Kurulum maliyeti çıkarıldığında 27.672,41 € net kar olacağı görülmektedir.

Paralelleme yapılmadığı durum ile 1000 m'de bir yapıldığı durum analizi: Tablo 3.1'de parallelleme yapılmadığı durumda çekilen toplam güç $789,28 \mathrm{~kW}, 1000$ m'de bir yapıldığı durumda ise $754,39 \mathrm{~kW}$ olarak verilmiştir. Bu durumda $34,89 \mathrm{~kW}$ 'lık bir kazanç ile günlük enerji tasarrufu 34,89*18 =628,02 kWh olmaktadır. Maddi açıdan sağlanan günlük kazanç değeri ise $628,02 * 0,54$ = 339,130 £ olarak hesaplanmıştır. Buna göre kablo maliyetinin karşılanma süresi yaklaşık 114 gündür. Katener hatları arasında 1000 m’de bir paralelleme yapılması durumunda, yılın sonunda sağlanan toplam kazanç 123.782,45 € olarak hesaplanmıştır. Bu kazançtan kurulum maliyeti çıkarıldığında bir yılın sonunda 85.142,45 £ net kar elde edileceği görülmektedir.

Paralelleme yapılmadığı durum ile 250 m'de bir yapıldığı durum analizi: Tablo 3.1'de parallelleme yapılmadığı durumda çekilen toplam güç 789,28 kW, 250 m'de bir yapıldığı durumda ise 734,46 kW olarak verilmiştir. Benzer hesaplama yöntemi ile maddi olarak günlük kazanç 532,850 €, kablo maliyetinin karşılanma süresi yaklaşık 267 gün, yılın sonunda sağlanan toplam kazanç 194.490,25 € ve bu kazançtan kurulum maliyeti çıkarıldığında bir yılın sonunda 52.074,25 € net kazanç elde edileceği görülmektedir.

Hangi sıklıkta paralelleme kablosunun daha avantajlı olduğununun iyi anlaşılabilmesi açısından ilk 3 yıllık kazanç Tablo 4.4 ’te gösterilmiştir.

Tablo 4. 4 Katener Hatlarının Paralellenmesinin Maliyet Analizi

\begin{tabular}{|c|c|c|c|c|c|c|c|c|c|}
\hline \multicolumn{10}{|c|}{ Paralelleme Kazanç Tablosu } \\
\hline & \multicolumn{3}{|c|}{$2000 \mathrm{~m}$} & \multicolumn{3}{|c|}{$1000 \mathrm{~m}$} & \multicolumn{3}{|c|}{$250 \mathrm{~m}$} \\
\hline & 1. yıl & 2. yil & 3. yll & 1. yll & 2. yil & 3. yll & 1. yll & 2. yıl & 3. yıl \\
\hline $\begin{array}{l}\text { Kurulum Maliyeti } \\
\text { (f) }\end{array}$ & $\begin{array}{c}18.768,0 \\
0\end{array}$ & 0 & 0 & $38.640,00$ & 0 & 0 & $142.416,00$ & 0 & 0 \\
\hline Kazanç (ł) & $\begin{array}{c}46.440,4 \\
1 \\
\end{array}$ & $\begin{array}{c}46.440,4 \\
1 \\
\end{array}$ & $46.440,41$ & $\begin{array}{c}123.782,4 \\
5 \\
\end{array}$ & $\begin{array}{c}123.782,4 \\
5\end{array}$ & $\begin{array}{c}123.782,4 \\
5\end{array}$ & $194.490,25$ & $\begin{array}{c}194.490,2 \\
5\end{array}$ & $\begin{array}{c}194.490,2 \\
5\end{array}$ \\
\hline Toplam Kazanç (も) & \multicolumn{3}{|c|}{$120.553,23$} & \multicolumn{3}{|c|}{ 332.707,35 } & \multicolumn{3}{|c|}{$441.054,75$} \\
\hline
\end{tabular}

\subsection{Ağırık Değişimi İçin Maliyet Analizi}

Tren toplam kütle değişiminin enerji tüketimine etkisinin gösterilmesi amacıyla bir maliyet analiz çalışması yapılmıştır. Enerji birim maliyeti $0,54 €$ / $\mathrm{kWh}$ olarak alınmıştır. Tablo 4.5 incelendiğinde tren toplam kütlesi yaklaşı \% 75 artarken, maliyetteki artışın $\% 32,74$ olduğu görülmektedir.

Tablo 4. 5 Tren Ă̆ırlık Dĕ̌̆işiminin Enerji Tüketimine Etkisi

\begin{tabular}{|c|c|c|c|c|c|}
\hline \multicolumn{7}{|c|}{ Tren Ağırık Değişiminin Enerji Tüketimine Etkisi } \\
\hline Yolcu Sayıs1 & Boş & 300 & 600 & 900 & 1200 \\
\hline Tren Ağırlığ1 $(\mathrm{Kg})$ & 119747,76 & 142247,82 & 164747,88 & 187247,76 & 209748,01 \\
\hline $\begin{array}{c}\text { Harcanan Enerji } \\
(\mathrm{kWh})\end{array}$ & 318,25974 & 347,79778 & 375,00335 & 400,24946 & 422,48408 \\
\hline Maliyet (£) & 171,86 & 187,81 & 202,501 & 216,134 & 228,141 \\
\hline
\end{tabular}

Birim maliyet analizi için kişi başına düşen enerji tüketimlerinin sonuçları Tablo 3.5'te paylaşılmıştır. Maliyet kısmında enerji tüketimi 0,54€ / kWh, gelir kısmında ise bir kişinin raylı topluma taşıma kullanım ücreti 1,5€ olarak alınmış ve hesaplamalar bu değerlere göre yapılmıştır.

Tablo 4. 6 Kişi Başına Düşen Enerji Tüketimi Açısından Maliyet Analizi

\begin{tabular}{|c|c|c|c|c|}
\hline \multicolumn{5}{|c|}{ Kişi Başına Düşen Enerji Tüketimi Açısından Maliyet Analizi } \\
\hline Yolcu Sayısı & 300 & 600 & 900 & 1200 \\
\hline $\begin{array}{c}\text { Enerji Tüketimleri } \\
\text { (kWh/kişi) }\end{array}$ & 1,159 & 0,625 & 0,444 & 0,352 \\
\hline Maliyet (Đ/kişi) & 0,6258 & 0,3375 & 0,2397 & 0,1901 \\
\hline
\end{tabular}




\begin{tabular}{|c|c|c|c|c|} 
Gelir (‡/kişi) & 1,5 & 1,5 & 1,5 & 1,5 \\
\hline Net Gelir (‡/kişi) & 0,8742 & 1,1625 & 1,2603 & 1,3099 \\
\hline
\end{tabular}

Tablo 4.6'da paylaşılan sonuçlara göre; trende 300 kişi seyehat ederken kişi başına tüketilen enerji $1,159 \mathrm{kWh}$ ve kişi başı net gelir 0,8742£ iken 1200 kişi taşınması durumunda 0,352 kWh tüketim ile 1,3099€ net gelir elde edildiği sonucuna varılmaktadır. Bu da 300 kişiye kıyasla 1200 kişilik yolcuğulun maliyet açısında yaklaşık \%49,84 daha avantajlı olduğunu göstermektedir.

\section{Sonuç}

$\mathrm{Bu}$ çalışmada, İstanbul şehiriçi raylı taşıma sisteminden seçilen örnek bir hat, RAILSIM DC simülasyon yazılımında modellenerek enerji verimliliğini artırma üzerine analizler gerçekleştirilmiştir. Bunlardan birincisi, katener hatları arasında paralelleme yapılmasının enerji tüketimi üzerinde etkisinin incelenmesidir. İkinicisi ise tren toplam kütle artışının enerji tüketimine etkilerinin incelenmesi olmuştur. Simülasyon çalışmalarının ardından her iki durum için de maliyet analiz çalışmaları yapılarak elde edilen sonuçlar sunulmuştur.

Katener hatlarının paralellenmesi durumu için gerçekleştirilen simülasyonlar sonucunda, modellenen hatta katener hatları arasında paralelleme olmadığı durumda çekilen güç değeri 789,28 kW iken her 250 metrede bir paralelleme olduğu durumda bu değerin \%6,94'lük bir azalma ile 734,46 kW'a düştügü gözlemlenmiştir. Aynı zamanda, hatların paralellenmesi gerilim düşümünü de azaltmaktadır. Her 250 metrede bir paralleme yapılması durumunda gerilim düşümü hatların hiç paralellenmemesi durumuna kıyasla \%10,06 oranında azalmıştır. Maliyet açısından da, incelenen senaryolar dikkate alındığında katener hatlarının 250 m’de bir sıklıkta parallenmesinin en avantajlı senaryo olduğu anlaşılmaktadır.

A ğırlık artışının enerji tüketimi üzerine etkisini incelemek için yolcusuz çalışma ile farklı sayıda yolcu kapasitesine sahipken çalışma durumları kıyaslanmıştır. 1200 kişilik yolculu durumda trenin toplam kütlesi yaklaşık \% 75 artarken, enerji tüketimindeki artış beklemeli çalışma durumda \%32,74 iken, beklemesiz çalışma durumda ise \%34,28 olmuştur. Yolcu sayısı arttıkça kişi başına düşen enerji tüketimi azalmaktadır. Enerji tüketiminin 300 yolculu durumda 1,111 kWh / kişi iken 1200 yolculu durumda 0,34 kWh / kişi'ye düştüğü görülmektedir. Kişi*km başına düşen enerji tüketimi ise 300 yolculu durumda 56,5 Wh iken 1200 yolculu durumda 17,28 Wh olmaktadır.

Katener hatlarının paralellenmesi ekonomik açıdan da avantaj sunmaktadır. Hatlar arasında hiçbir paralelleme yapılmaması durumuna kıyasla her 250m’de bir paralallenmesi durumunda yıllık 194.490,25€ tasarruf elde edileceği hesaplanmıştır. Kurulum maliyeti çıkarıldığında ise 3 yılın sonunda 441.054,75£ net kar elde edileceği görülmektedir. Ağırlık değişimi ile ilgili maliyet analizi incelendiğinde, trenler 300 yolcuya kıyasla 1200 yolcu ile hareket ettiklerinde kişi başına düşen enerji tüketim miktarının azaldığı ve trenlerin yaklaşık \%49,84 daha avantajlı hareket ettiği sonucuna ulaşılmaktadır.

Gerçekleştirilen çalışma sonucunda, gerek tasarım gerekse işletim esnasında yapılacak değişimler ile raylı sistemlerde enerji verimliliğinin arttırılabileceği ve önemli maddi kazanımlar sağlanabileceği ortaya konulmuştur. İşletmede olan ve yeni kurulacak olan hatlar için de benzer analizlerin yapılmasının gerek enerji verimliliği gerekse ekonomi açısından faydalı olacağı görülmüştür. İleriki çalışmalarda, diğer enerji verimliliği yöntemlerinin etkilerinin de analiz edilmesi planlanmaktadır.

\section{Kaynakça}

[1] Gonzalez-Gil, A., Palacin, R., Batty, P. ve Powell, J.P. (2014). "A system aproach to reduce urban rail energy consumption", Energy Conversion and Management, 80: 509-524.

[2] Official Journal of the European Union, Decision No 406/2009/EC on the effort of Member States to reduce thei greenhouse gas emissions to meet the Community's greenhouse gas emission reduction commitments up to 202;2009. <http://eurlex.europa.eu/LexUriServ/LexUriServ.do?uri=OJ:L:2009: 140:0136:0148:EN:PDF>.

[3] European Commission, A Roadmap for moving to a competitive low carbon economy in 2050 - Ref. COM(2011) 112 final; 2011. <http://www.eurlex. europa.eu/LexUriServ/LexUriServ.do?uri=COM:2011:0112:FIN:EN:PDF>.

[4] Lamedica, R., Ruvio, A., Galdi, V., Graber, G., Sforza, P., GuidiBuffarini, G. ve Spalvieri C., (2015). “Application of battery auxiliary substations in 3kV railway systems", AEIT International Annual Conference, 14-16 Oct. 2015, Naples, 1-6.

[5] Açıkbaş, S., (2008). Çok Hatlı Çok Araçlı Raylı Sistemlerde Enerji Tasarrufuna Yönelik Sürüş Kontrolü, Doktora Tezi, İTÜ Fen Bilimleri Enstitüsü, İstanbul.

[6] Chang, C.S. and Sim, S.S., (1997). "Optimising train movement through coast control using genetic algorithm", IEE Proc.-Electr. Power Applications, 144: 65-73.

[7] Howlett, P.G., (2000). "The Optimal control of a train", Annals of Operations Research, 98: 65-87.

[8] Ke, R., Chen, M.C. ve Lin, C.L., (2009). "Block-Layout Design Using MAX-MIN Ant System for Saving Energy on Mass Rapid Transit Systems", IEEE Transactions on Intelligent Transportation Systems, 10: 226-235.

[9] Miyatake, M. ve Ko, H., (2009). "Optimization of Train Speed Profile for Minimum Energy Consumption", IEEJ Transacitons on Electrical and Electronic Engineering, 5: 263-269.

[10]Bocharnikov, Y.V., Tobias, A.M., Roberts, C., Hilmansen, S. ve Goodman, C.J., (2007). "Optimal Driving Strategies for traction energy saving on DC Suburban railways", IET Electr Power Applications, 1: 675-682.

[11]Albert, H., Levin, C., Vietrosa, E. ve Witte, G., (1995). "Reducing energy consumption in underground systems", September.

[12]Hartland, D., (2012). "Heating the countryside or saving the kilowatt hours", IMechE Railway division seminar gaining traction in energy efficiency, 2012, London. 
[13]Andrade Jr, R., Ferreira, A.C., Sotelo, G.G., Suemitsua, W.I., Rolima, L.G.B., Silva Netoa, J.L., Nevesa, M.A., Dos Santos, V.A., Da Costa, G.C., Rosario, M., Stephan, R. ve Nicolskya, R., (2004). “A superconducting high-speed flywheel energy storage system", Physica C Superconductivity, 408-410: 930-931.

[14]Eickhoff B. ve Nowell R., (2011). "Determining the benefit of train mass reduction", A More and More Energy Efficient Railway, 24 May 2011, London.

[15]Açıkbaş, S. ve Söylemez, M.T., Catenary System Paralelling and Its Effect on Power Consumption and Regenerated Energy Recuperation, http://www.emo.org.tr/ekler/2d081df1f0040ac_ek.pdf, 15 Mart 2018.

[16]Açıkbaş, M. Ve Söylemez, M.T., (2004), Energy Loss Comparison Between 750 VDC and 1500 VDC Power Supply Systems Using Rail Power Simulation, https://www.witpress.com/elibrary/wit-transactions-on-the-built-environment/74/12124, 2 Ocak 2018.

[17]Zhang, W. ve Wei, J., (2012). "The experimental research on Beijing subway air-conditioning system energy-saving", Applied Mechanics and Materials, 170: 2494-2498.

[18]Fuertes, A., Casals, M., Gangolells, M. ve Puigdollers, O., (2012). "Overcoming challanges for energy management in undergorund railway stations", European conference on product and process modelling, 6 July 2012, Reykjavik.

[19]Sarıkavak, Y. (2018). Demiryolu endüstrisinde akıllı ulaştırma sistemleri ve Türkiye'deki uygulama örnekleri. Akıllı Ulaşım Sistemleri ve Uygulamaları Dergisi, 1 (2), 22-32. Retrieved from http://dergipark.org.tr/jitsa/issue/39569/455153.

[20]http://www.hes.com.tr/images/user_uploaded_files/FiyatListesi.pdf 